\title{
Autologus Hair Transplantation Vs Skin Expansion in Management of Cicatricial Alopecia; A Comparative Study
}

\author{
Mohamed Hassan Mohamed Abdel-Aal, Ahmed Abo Hashem Azab, Amr Mohamed Mohamed Adss* \\ Department of General Surgery, Faculty of Medicine, Zagazig University \\ * Corresponding author: Amr Mohamed Mohamed Adss, Mobile: (+20)01001890194, E-mail: amrads92@ gmail.com
}

\begin{abstract}
Background: The bad impact of cicatricial alopecia among population lead to increase the desire of correction of that type of hair loss. Although, there are many methods of hair restoration but the efficacy of each, indications and possible hazards has not yet been clearly identified.

Objective: To compare between hair transplantation using follicular unit extraction and skin expansion surgeries in the field of hair restoration in secondary cicatricial alopecia regarding aesthetic outcome, operative duration, optimum patient selection and complications of both techniques.

Subjects and methods: Twenty four patients suffering from alopecia were involved in this study 15 males $(62.5 \%)$ and 9 females (37.5\%). Patient's age ranged from 7 to 26 years old. Patients were divided into two groups according to the procedure done. Group (A) 12 patients done hair transplantation surgeries. Group (B) 12 patients done scalp expansion surgeries. Results: There was a non-significant difference between both groups regarding the mean age or the mean operation duration $(\mathrm{P}>0.05)$. The mean values of the surface area of alopecia, in tissue expander group (B) was significantly larger than that of hair transplantation in group (A) $(\mathrm{P}<0.001)$. However the time since exposure to the causative injury was significantly longer in group (A) than that of group (B) $(\mathrm{P}<0.01)$. Hair transplantation tends to have less recovery time highly indicated in adults with smaller non-dependent areas of alopecia, while expanders with long recovery period solve bigger problems of alopecia in younger patients.

Conclusion: Multiple factors interfere with the surgical plan age, gender, occupation, size and site of alopecia and time since injury. Both hair transplantation and skin expansion are very useful in the field of cicatricial alopecia treatment. While hair transplantation has less hazards during anesthesia, less post-operative scars and less recovery time, skin expansion is a good solution for bigger problems like big area of alopecia or younger patients. Keywords: Alopecia, hair transplantation, skin expansion and hair restorative surgeries.
\end{abstract}

\section{INTRODUCTION}

The term "cicatricial alopecia" refers to a scarring that ends up with loss of hair that outcomes from a various set of disorders that devastate the hair follicle, substitute it with scar tissue and cause persistent hair loss ${ }^{(\mathbf{1})}$. Cicatricial alopecias are sorted as primary and secondary. In primary cicatricial alopecias the stable portion of the hair follicle (stem cells of the bulge area and the infundibulum) is the target of the destructive inflammatory course and the cause varies from autoimmune diseases like lichen Plano pilaris (LPP), discoid lupus erythematosus (DLE), pseudopelade of Brocq, to infections like folliculitis decalvans (2). Secondary cicatricial alopecias, result from damage of the hair follicle subsidiary to a non-follicle-directed process or external injury, such as burns, radiation, trauma or severe infections like tinea capitis ${ }^{(3)}$.

Surgical correction of cicatricial alopecias is highly valuable. While the affected area is most often treated with hair transplantation. Alternative approaches include alopecia reductions (the excision of the hairless region) and or flap procedures, alone or sometimes in conjunction with hair transplantation ${ }^{(\mathbf{1})}$. Hair transplant consists of harvesting hair from a donor area (usually the occipital and postero-parietal scalp) using a single strip excision or small punch excisions used to harvest individual follicular units (FUE) and grafting them into the recipient site ${ }^{(4)}$.
Neumann et al. ${ }^{(5)}$ reported the first clinical use of tissue expansion in 1957 when he expanded the scalp for ear reconstruction. In 2005, Leedy et al. reported reconstruction of nearly half the scalp with hair-bearing tissue using tissue expansion ${ }^{(6)}$. Surgical excision of scarred areas over the scalp used to treat small areas of scarring alopecia, to treat larger areas (scars wider than $5 \mathrm{~cm}$ ), tissue expanders may be inserted in the normal scalp adjacent to the scarred area and progressively filled with saline over $8-12$ weeks. The stretched hair-bearing skin is then advanced, or rotated, to fill the surgical defects created by excision of scarred areas ${ }^{(7)}$. Excision of scar tissue has the following advantages: can be performed in one session, is not dependent on donor area and doesn't depend on graft survival. Although, it has some disadvantages including multiple linear scars and having high rate of complications. Skin expanders can treat large areas but may need maultiple sessions. On the other hand, hair transplant has advantages including one linear strip in follicular unit transection, minimal scarring in folicular unit extraction and lower rate of complications. While, the disadvantages include that it requires good donor area, may induce koebnerization, might need multiple sessions and graft survival might be suboptimal ${ }^{(8)}$.

Aim of the work: The study aimed to compare between hair transplantation using follicular unit extraction and skin expansion surgeries in the field of 
hair restoration in secondary cicatricial alopecia regarding aesthetic outcome, operative duration, optimum patient selection and complications of both techniques.

\section{Subject and methods}

This study was conducted in the Department Of Plastic and Reconstructive Surgery, Faculty of Medicine, Zagazig University through the period from September 2017 to September 2018. Twenty four patients suffering from alopecia were involved in this study 15 males (62.5\%) and 9 females (37.5\%). Patient's ages ranged from 7 to 26 years old. Patients were divided into two groups according to the procedure done.

Ethical approval and written informed consent: An approval of the study was obtained from Zagazig University academic and ethical committee. Every patient signed an informed written consent for acceptance of the operation.

\section{Operative}

\section{GROUP (A) (Hair Transplantation group):}

Hair shaving on a length of $1 \mathrm{~mm}$ over the skin. The patient lies on prone position with elevation of the table head to avoid head and neck congestion or sits with head leaning forward on table.

Anaesthesia and tumescese of the donor area: Occipital and post auricular nerve blockage was obtained with bupivacaine hydrochloride. Infiltration anesthesia was done with a solution containing lidocaine, adrenalin and sodium bicarbonate. Physiological serum with lidocaine and adrenalin was used as a tumescent solution to inflate the graft donor areaas shown in figure $(1)^{(9)}$.

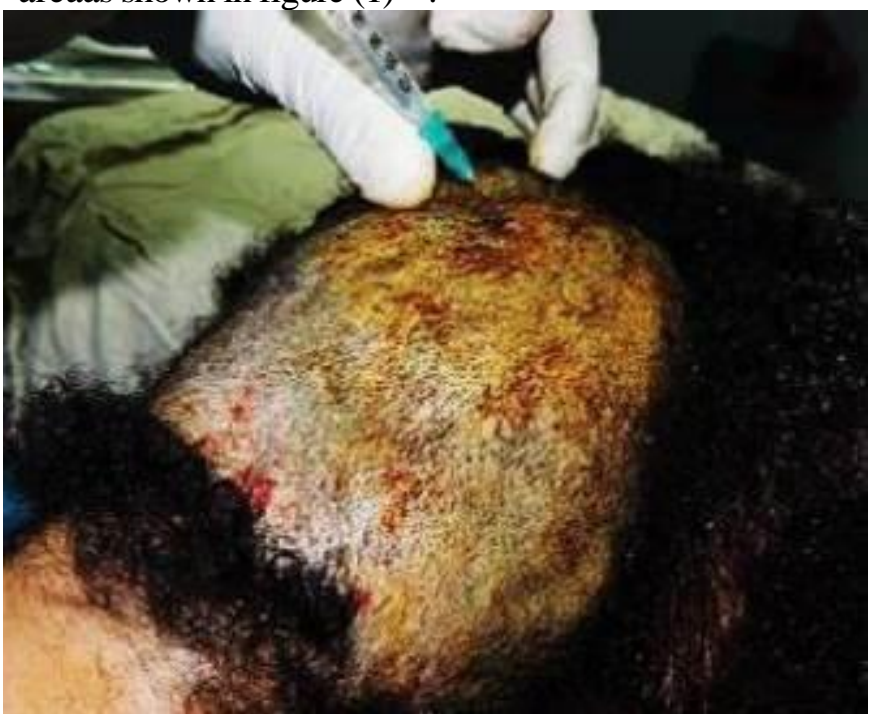

Fig. (1): Injection of local anaesthesia

Operative procedures: We used the follicular unit extraction (FUE) technique and the powered SAFE System developed by Dua and Dua ${ }^{(10)}$ (Figure 2).

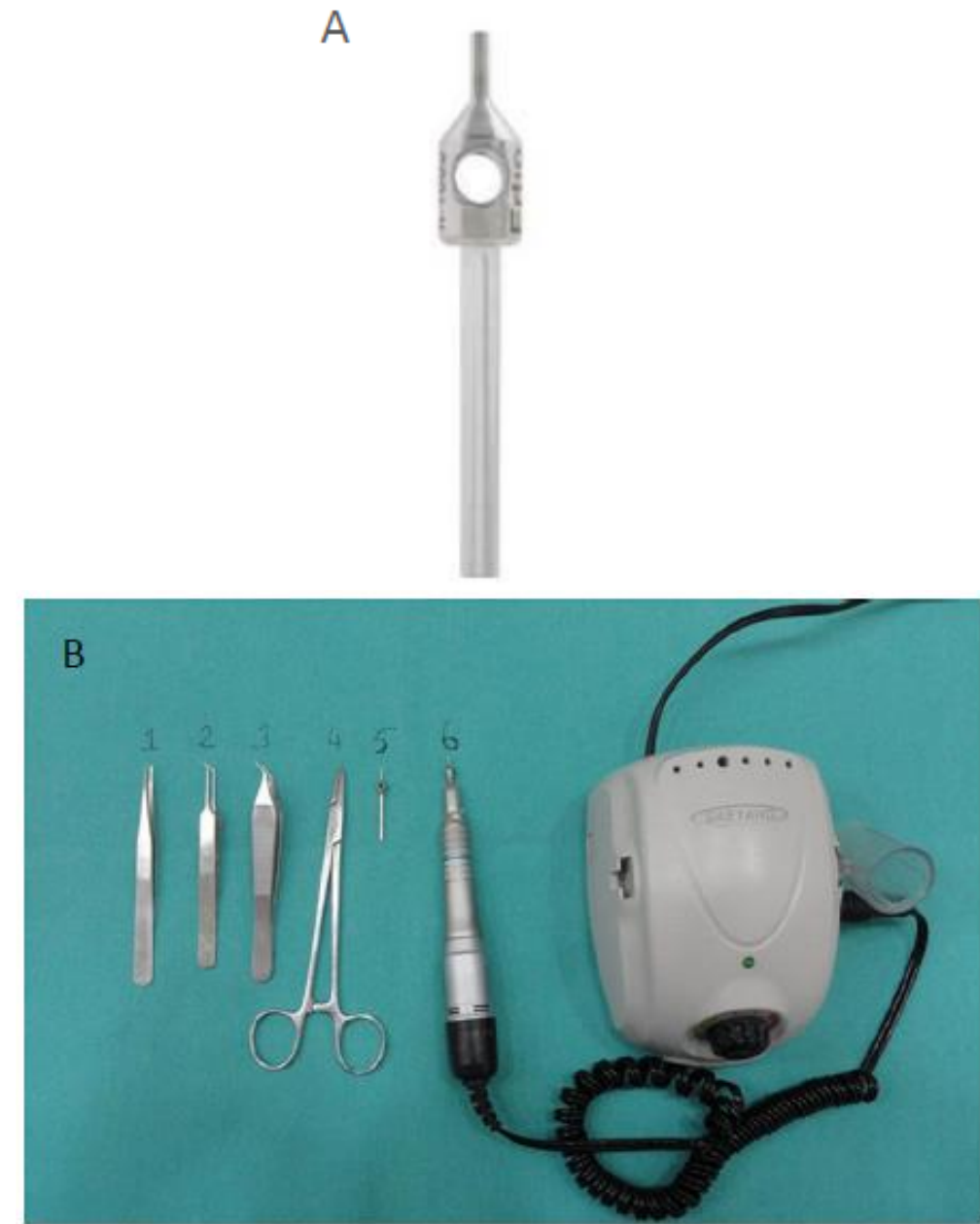

Fig. (2): Instruments used in hair transplantation (A) and punch used for extraction of follicles (B) whole set of instruments.

Each punch is advanced into the dermis (approximately $2 \mathrm{~mm}$ ) with care not to enter into the subcutaneous space. After the punch incision is made, serrated forceps are used to apply gentle pressure on the skin around the graft, elevating it lightly to allow the top part of the graft to be grasped using fine angled jeweller's forceps.

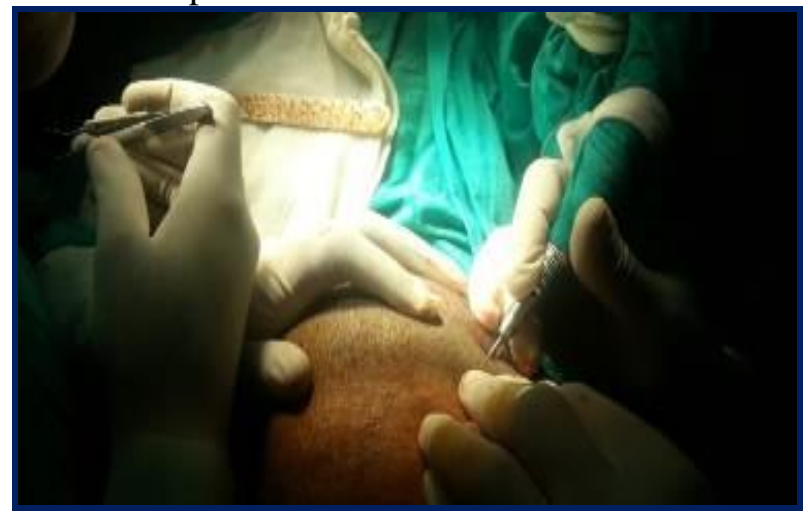

Fig. (3): FUE technique 


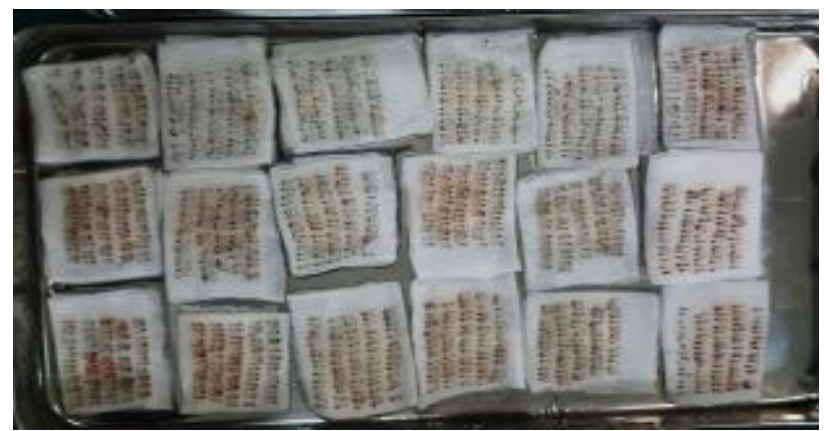

Fig. (4): Extracted grafts spread on wet gausses.

The extracted grafts are to be examined to determine if the entire shaft came out intact or if hair fragments are produced. Then they are arranged in rows on sterile wet gause to be classified and sorted according to size (the number of presumed hairs contained in the original follicular unit).

\section{Implantation of the follicles: Instruments: -} Cannula No. 16. - Fine Jewellers.
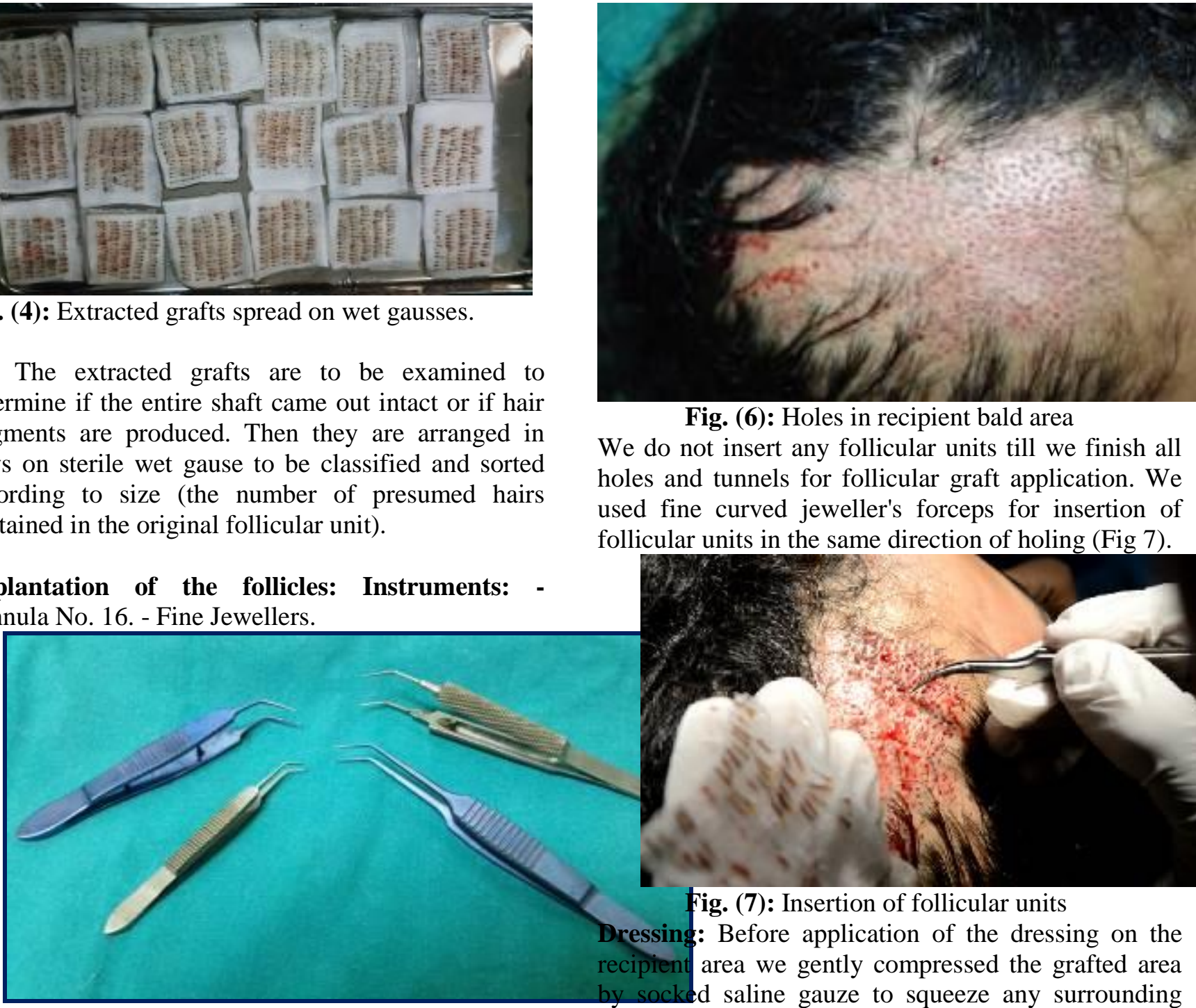

Fig. (6): Holes in recipient bald area

We do not insert any follicular units till we finish all holes and tunnels for follicular graft application. We used fine curved jeweller's forceps for insertion of follicular units in the same direction of holing (Fig 7).
Fig. (5): Jeweller's forceps

Supine position till we finish towelling. Then, semi sitting position just before operative intervention to avoid head and neck congestion or sitting lying his head on the table, then photographing of recipient area is done.

Anaesthesia: We used xylocaine local infiltration anaesthesia as mentioned before in harvesting of the graft. We used tumescent infiltration (xylocaine 2\%, adrenaline 1:100,000 and saline) to be injected subcutaneously in subgaleal and supraperiosteal plane (loose areolar connective tissue), which expanded rapidly and pressed on blood vessels of the scalp in the injected area. The manoeuvre gave us bloodless field and good haemostasis.

Insertion of the grafts: We start by making holes (510) minutes after ballooning to make sure that there was complete sensory loss of the recipient area. We used trocar of cannula no.16 to do a round hole in the recipient bald area in patients with a distance of 1.5 $\mathrm{mm}$ between each hole as shown in figure (6). micro haematoma around the follicular graft, otherwise graft take would be endangered (Fig 8).

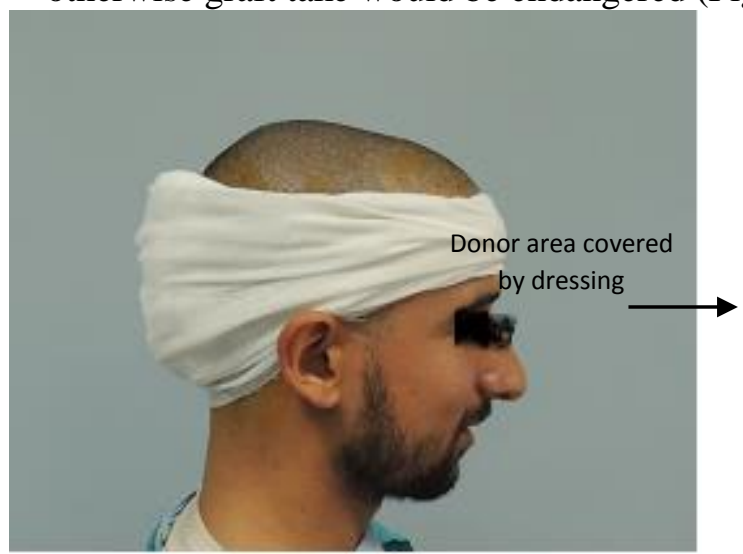

Fig (8). Postoperative dressing

All patients were given broad spectrum antibiotics sulbctam and amoxicillin $1.5 \mathrm{gm}$ vial IV for one week. Oral analgesic is prescribed in the form of NSAIDs (ibuprofen $600 \mathrm{mg}$ tab t.d.s.) for one week. Some patients are advised to put ice bags over the eyes and forehead for the 1 st 48 hours to prevent oedema. The first Post-operative dressing was done 3 days later, the patient came to the Outpatient Clinic and the dressing was removed very slowly under running 
saline. The patients started washing the scalp by antidandruff shampoo 3 days after dressing removal. Patients are given vitamin $\mathrm{B}_{7}$ (Biotin $10000 \mathrm{IU}$ ) once daily for 6 months. Two cases received monthly platelet rich plasma injection to the recipient area for 6 months.

\section{Tissue expansion group (B)}

The expanders which were chosen were larger than the defect in the neighboring proper sites for expansion. We used rectangular expanders with semi hard base and remote filling port. Their size varied from $250 \mathrm{cc}$ to $400 \mathrm{c}$. With the patient in the supine position, general anesthesia was given. Incision was made at the border between healthy and scar tissue, sub cutaneous dissection to form pocket for tissue expander then insertion of tissue expander under healthy skin area and closure of the incision in layers. After 8 to 12 weeks of skin expansion, patient was prepared for second session. Incision at the edge between healthy and scar tissue. Tissue expander extraction and scar tissue excision then expanded skin flap advancement or rotation to fill the defect left by excised scar tissue

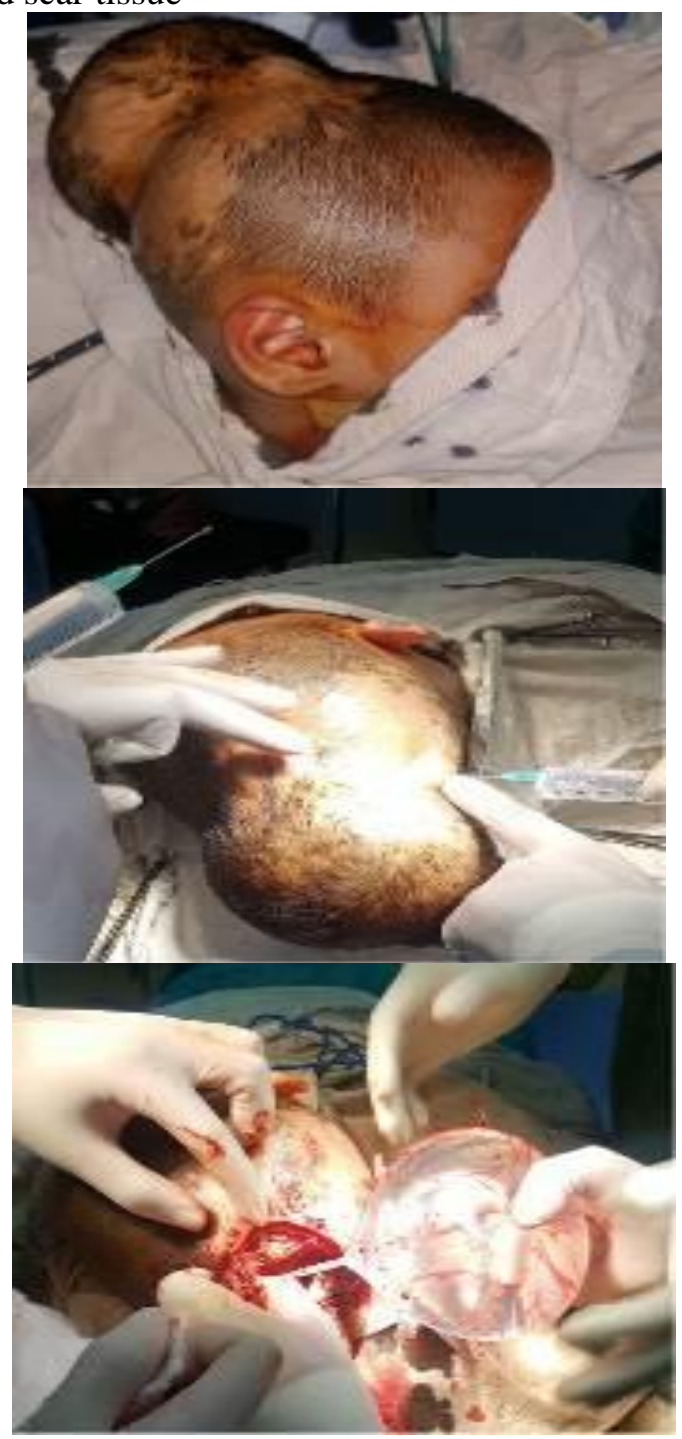

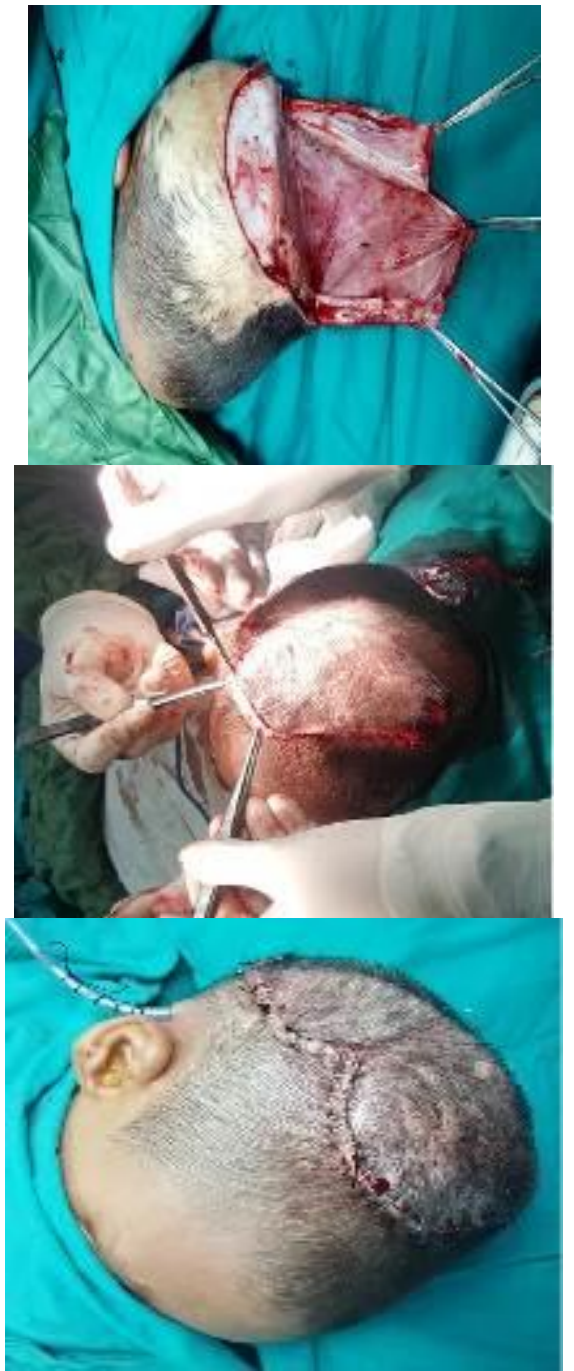

Fig (9): Operative steps of expander removal and expanded flap insetting after alopecic area excision All patients were given broad spectrum sulbctam and amoxicillin $1.5 \mathrm{gm}$ vial IV for one week. Oral analgesic is prescribed in the form of NSAIDs (ibuprofen $600 \mathrm{mg}$ tab t.d.s) for one week. $\mathrm{H}_{2}$ blocker (Ranitidine $150 \mathrm{mg}$ Tablet) twice daily is prescribed to prevent any gastrointestinal upset with medication. The patients start washing the scalp by shampoo 3 days after dressing removal. Photographing of both donor and recipient areas at every visit.

\section{Statistical analysis}

Recorded data were analyzed using the statistical package for social sciences, version 20.0 (SPSS Inc., Chicago, Illinois, USA). Quantitative data were expressed as mean \pm standard deviation (SD). Qualitative data were expressed as frequency and percentage.

\section{The following tests were done:}

- Independent-samples t-test of significance was used when comparing between two means.

- Chi-square $\left(\mathrm{x}^{2}\right)$ test of significance was used in order to compare proportions between two qualitative parameters. 
- The confidence interval was set to $95 \%$ and the margin of error accepted was set to $5 \%$. The p-value was considered significant as the following:

- Probability (P-value)

P-value $<0.05$ was considered significant.

P-value $<0.001$ was considered as highly significant.

\section{RESULTS}

In comparing the two procedures, there was a non-significant difference between both groups regarding the mean age or the mean operation duration $(\mathrm{P}>0.05)$ as shown in table (1).

P-value $>0.05$ was considered insignificant.

Table (1): A Comparison between the two operated groups regarding age, sex, residence and occupation.

\begin{tabular}{|c|c|c|c|c|c|c|}
\hline \multirow{2}{*}{\multicolumn{2}{|c|}{ Items }} & \multicolumn{2}{|c|}{ Group (A) } & \multicolumn{2}{|c|}{ Group (B) } & \multirow[t]{2}{*}{$P$ value } \\
\hline & & No & $\%$ & no & $\%$ & \\
\hline \multirow[t]{3}{*}{ Age } & $<15$ & 0 & 0.00 & 6 & 50 & \multirow[t]{3}{*}{0.141} \\
\hline & $15-25$ & 12 & $100 \%$ & 5 & 41.67 & \\
\hline & $>25$ & 0 & 0.0 & 1 & 8.33 & \\
\hline \multirow[t]{2}{*}{ Sex } & Male & 9 & 75 & 6 & 50 & \multirow[t]{2}{*}{0.091} \\
\hline & Female & 3 & 25 & 6 & 50 & \\
\hline \multirow[t]{2}{*}{ Residence } & Rural & 5 & 41.67 & 6 & 50 & \multirow[t]{2}{*}{0.558} \\
\hline & Urban & 7 & 58.33 & 6 & 50 & \\
\hline \multirow[t]{4}{*}{ Occupation } & Student & 2 & 16.67 & 3 & 25 & \multirow[t]{4}{*}{0.642} \\
\hline & House wife & 1 & 8.33 & 3 & 25 & \\
\hline & Clerks & 4 & 33.33 & 2 & 16.67 & \\
\hline & $\begin{array}{l}\text { Manual } \\
\text { workers }\end{array}$ & 5 & 41.67 & 4 & 33.33 & \\
\hline
\end{tabular}

The mean values of the surface area of alopecia in group (B) was significantly larger than that in group (A) (P< 0.001). However, the time since exposure to the causative injury was significantly longer in Group (A) than that of Group (B) $(\mathrm{P}<0.01)$.

Table (2): A Comparison between the two operated groups regarding the mean values of age, surface area of alopecia, time since injury and operative duration.

\begin{tabular}{||l||l||l||l||l||}
\hline & Group (A) & Group (B) & t test & P value \\
\hline \hline Age (year) & $19.00 \pm 2.92$ & $16.00 \pm 6.14$ & 1.526 & 0.141 \\
\hline Surface area of alopecia $\left(\mathrm{Cm}^{2}\right)$ & $19.83 \pm 13.30$ & $142.00 \pm 47.04$ & 8.657 & 0.0000 \\
\hline Time since injury (years) & $12.08 \pm 6.26$ & $4.66 \pm 2.42$ & 3.828 & 0.001 \\
\hline Operative duration (hour) & $3.12 \pm 1.42$ & $4.12 \pm 1.08$ & 1.93 & $0.065(\mathrm{NS})$ \\
\hline
\end{tabular}

Table (3): The statistical analysis of group (A) procedure (The number of estimated hair follicles needed \& the number of sessions) and group (B) procedure (The estimated expander size $\&$ the maximal size of the expander reached)

\begin{tabular}{|c|c|c|c|}
\hline \multirow{5}{*}{ 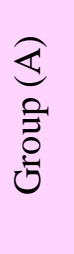 } & \multirow{3}{*}{$\begin{array}{l}\text { Number of estimated hair follicles } \\
\text { needed }\end{array}$} & range & $150-1200$ \\
\hline & & mean & 441.67 \\
\hline & & SD & 308.09 \\
\hline & \multirow[t]{2}{*}{ Number of sessions } & one & $11(91.67)$ \\
\hline & & Two & One $(8.33 \%)$ \\
\hline \multirow{6}{*}{ 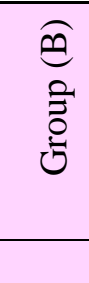 } & \multirow[t]{3}{*}{ Estimated expander size } & range & $250-400 \mathrm{CC}$ \\
\hline & & mean & 312.50 \\
\hline & & SD & 60.77 \\
\hline & \multirow{3}{*}{$\begin{array}{l}\text { the maximal size of the expander } \\
\text { reached }\end{array}$} & range & $400-1100 \mathrm{CC}$ \\
\hline & & mean & 725 \\
\hline & & SD & 208.48 \\
\hline
\end{tabular}


Regarding complications, in group (A), while the donor sites showed no complications (white scar, pseudo-syphilitic appearance or necrosis), there was a minor complications in the recipient sites in the form of failure of plantation $(8.33 \%$, one case), hair thinning $(8.33 \%$, one case), un-satisfaction $(8.33 \%$, one case). In group (B) there were seroma in 2 cases $(16.67 \%)$, hematoma in one case $(8.33 \%)$, loss of expander in one case $(8.33 \%)$ and no patchy alopecia over expanded flap or unsatisfied patient were detected.

There were no significant association between the size of alopecia and incidence of complications ( $p$ values of Fisher's exact test were 0.59 and 0.64 respectively). In addition, $p$ values of Pearson Chi- square were 0.08 and 0.55 respectively). Furthermore, no association could be detected between operative duration and incidence of complication, as $\mathrm{p}$ value of Fisher's exact test was 0.076 and $p$ value of Pearson Chi- square was 0.08 .

Regarding patient questionnaires regarding the results and patient satisfaction. In General no patient assigned excellent results in both groups $(0 \%)$, very good results reported in 7 cases $(58.33 \%)$ in group (A) \& 8 cases $(66.67 \%)$ in group (B), good results was revealed in 4 cases $(33.33 \%$ ) in group (A) \& 3 cases of group (B) $(25.0 \%)$ and bad results in one case of each group $(8.33 \%)$.

In concern to hair density, no patient assigned excellent results in both groups $(0 \%)$, very good results were reported in one case $(8.33 \%)$ in group (A) $\& 8$ cases $(66.67 \%)$ in group (B), good results were revealed in 10 cases $(83.33 \%$ ) in group (A) \& 4 cases of group (B) (33.33\%), no bad results in both groups $(0.0 \%)$ and poor results was detected in one case of group (A) (8.33\%).

Hidden postoperative scars in general was very good in 8 cases $(66.67 \%$ ) in group (A) \& 4 cases of group (B) $(33.33 \%)$, good results were found in 3 cases $(25.0 \%)$ in group (A) \& 5 cases of group (B) $(41.66$ $\%$ ) and bad results were in one case of group (A) $(8.33 \%) \& 3$ cases of group (B) (25.0\%). Finally advice for other patient to do this surgery from current cases: very good reported in five cases $(41.66 \%)$ in group (A) \& 4 cases (33.33\%) in group (B) and good recommendation was revealed by 6 cases $(50.0 \%)$ in group (A) \& 7 cases of group (B) (58.33\%).

\section{DISCUSSION}

Hair transplantation surgery is the cosmetically relevant therapy currently that can permanently give back naturally looking scalp hair in patients, where medication is not an option. However, the quality of the result is highly dependent on the patient (age, availability of grafts and prospected progress of alopecia) and the technique of the surgeon. Although, there is a great variation in how surgeons perform aspects of the transplantation procedure in detail, the strategy used for the obtainment of grafts, in both cases being intact follicular units (FUs), roughly defines 2 techniques: follicular unit transplantation (FUT) and follicular unit extraction (FUE) ${ }^{(\mathbf{1 1})}$.

As with all procedures, the consult is vital to establish candidate selection. Patients with increased donor density, thick-caliber hair follicles and areas of clear thinning in the frontal scalp are ideal candidates for the procedure. Those with limited donor density and fine thin-caliber hair follicles will have less cosmetic impact from a procedure ${ }^{(\mathbf{1 2})}$.

Scarring alopecias from secondary causes, such as burns, surgery and trauma are mostly amenable to hair transplantation. Follicular unit grafts transplanted over scars in hair-bearing areas provide camouflage resulting in an improved cosmetic appearance, especially in highly visible areas, such as the scalp. Important considerations include wider spacing of grafts compared with regular hair transplantation of androgenetic pattern hair loss because of the decreased vascularity over these scarred areas. Staged procedures can be done to increase density and improve coverage ${ }^{(13)}$. Successful outcomes have been observed with follicular unit transplantation to hide scars and restore hairs lost from rhytidoplasty and other plastic surgeries ${ }^{(\mathbf{1 4})}$.

On the other hand, Expanding normal skin using tissue expanders has become a good solution for postburn alopecia, with excellent results ${ }^{(15)}$. Expanders have been proved to be fruitful in the pediatric population. In particular, scalp expansion has proved to be useful in the reconstruction of posttraumatic and post-burn alopecic defects ${ }^{\left({ }^{(6)}\right.}$. Tissue expansion could provide an excellent alternative to hair transplantation in cases of skin grafts to the cranium, there would be virtually no underlying soft tissue so follicular unit transplantation might not provide satisfactory results or may result in necrosis ${ }^{(17)}$.

Shao et al. ${ }^{(18)}$ carried their study on 37 patients suffering from secondary cicatricial alopecia in a duration of 5 years. In our study we studied 12 patients operated by hair transplantation in a period of 12 months this might be due to rare presentation of the patients and longtime of follow up needed for these patients.

In group (B), our study involved 12 patients were operated upon and their data were collected retrospectively, Tayyaba et al. ${ }^{(19)}$ studied 30 patients of scalp cicatricial alopecia and treated them with tissue expansion in a duration of one year this might be due to frequent injuries at this area (Pakistan) due to recent civil strikes at 2013-2014.

Regarding patient's mean age in group (A), it was $19.00 \pm 2.92$ years. While Shao et al. ${ }^{\mathbf{1 8})}$ showed mean age of $24.68 \pm 5.88$ years. This difference might be due to bigger sample size. 
In group $\mathrm{B}$, patient's mean age was $16 \pm 8.32$ years. Tayyaba et al. ${ }^{\left({ }^{(9)}\right.}$ had mean age of patients treated by skin expansion $21.13 \pm 10.06$ years.

In this study concerning group $\mathrm{A}$, the mean surface area of alopecia $\left(\mathrm{Cm}^{2}\right)$ was $19.83 \pm 13.30$, which differs from results reported by Shao et al. ${ }^{(17)}$ as surface area of recipient site has the mean of 10.08 \pm 19.55 . This might be due to their case selection (choosing patients with small linear scalp scars).

In group $B$, the mean surface area was $142 \pm$ 47.04, while Handschel et al. ${ }^{(20)}$ studied 40 patients with mean surface area $40 \pm 4.3$. This was due to totally different patients as they studied patients after radiotherapy which led to smaller scalp alopecic areas.

In current study, the mean duration of hair transplantation, in group A was $3.12 \pm 1.42$, Shao et al. ${ }^{(18)}$ has a similar range of operative duration (3.61 \pm 1.32).

In the current study concerning group $\mathrm{A}$, the mean follicular unit density per recipient area was $22.03 \pm 3.26 \mathrm{fu} / \mathrm{cm}^{2}$ while Shao et al. ${ }^{(17)}$ had the mean density of $36.28 \pm 6.44 \mathrm{fu} / \mathrm{cm}^{2}$. The difference was due to our consideration of the poor vascularity of the recipient areas so we didn't overcrowd the follicular units during implantation.

While in group $\mathrm{B}$, the mean expansion volume was 312.50, Handschel et al. ${ }^{(20)}$ had mean expansion volume of $224 \pm 189.03$ this might be due to relatively smaller alopecic areas he included in his study.

In this study, group A patients had a complication rate of $25 \%$ while Shao et al. ${ }^{(18)}$ had only $5.6 \%$ incidence of complication. This difference might be because they only mentioned long term complications including 2 patients out of 37 patients having epidermoid cyst formation.

In Group B we faced complications in $25 \%$ of the patients, Tayyaba et al. (19) faced $46.67 \%$ complication incidence. In addition, he had incidence of $26 \%$ of mild infections.

It is worthy to say that there is great versibility in the recorded incidences of complications in expander surgeries. As Kim et al. (21) faced complications of $12.8 \%$ in their series of 62 patients. They relied this low incidence of complications due to strict measures in postoperative care. Similarly, Chen $\boldsymbol{e t}$ al. ${ }^{(22)}$ stated that complications of the use of tissue expanders are controversial, having complication incidence of $6.25 \%$. He compared his results to that of Qing $\boldsymbol{e t}$ al. (23) who faced $14 \%$ incidence of complications in a study of 57 patients and also to Saleh et al. (24) who faced complication rate of $21.5 \%$ in their study.

Regarding group A, patients' satisfaction showed very good results reported in 7 cases $(58.33 \%)$, good results was revealed in 4 cases $(33.33 \%)$ and poor results in one case of (8.33\%). Rahimi et al. (25) showed excellent results in $10 \%$, good results in $70 \%$ and satisfactory results in $20 \%$ of patients. While,
Shao et al. ${ }^{(18)}$ stated that patients' satisfaction at their study was $100 \%$ for 30 patients, $90 \%$ to $100 \%$ for five patients and $<90 \%$ for two patients.

While in Group B, patients' satisfaction was very good in $66.67 \%$, good in $25 \%$ and poor results in $8.33 \%$ of the patients.

\section{CONCLUSION}

Autologous hair transplantation or tissue expansion are exquisite methods for achieving feasible reconstruction of the scalp in the cicatricial alopecia. Meticulous attention to every step starting from patient selection ending by careful follow-up are necessary to reduce the incidence of complications and improve the outcome.

For that, the choice of management plan for such patients need special consideration to the cause, age, site of alopecia, area of alopecia and also to the socioeconomic status of the patient as the use of tissue expander is of higher cost. Also combination of both procedures in the same case would give higher results.

Both hair transplantation and skin expansion are very useful in the field of cicatricial alopecia treatment, while hair transplantation has less hazards during anesthesia, less post-operative scars and less recovery time, skin expansion is a good solution for bigger problems like big area of alopecia or younger patients.

\section{REFERENCES}

1. Ross EK, Tan E, Shapiro J (2005): Update on primary cicatricial alopecias. Journal of the American Academy of Dermatology, 53 (1): 1-37.

2. Tan E, Martinka M, Ball N et al. (2004): Primary cicatricial alopecias: clinicopathology of 112 cases. Journal of the American Academy of Dermatology, 50 (1): 25-32.

3. Sowjanya CL, Rao TN, Guruprasad P et al. (2012): Clinico-pathological study of acquired primary cicatricial alopecias. Journal of NTR University of Health Sciences, 1 (1): 21.

4. Meyer-Gonzalez T, Bisanga C (2012): Body-hair transplant for cicatricial alopecia. Actas DermoSifiliográficas (English Edition), 103 (2): 163-165.

5. Neumann CG (1957): The expansion of an area of skin by progressive distension of a subcutaneous balloon. Plast. Reconstr. Surg., 19: 124-129.

6. Leedy JE, Janis JE, Rohrich RJ (2005): Reconstruction of acquired scalp defects: an algorithmic approach. Plastic and Reconstructive Surgery, 116 (4): 54-72.

7. Dahdah MJ, Iorizzo M (2016): The role of hair restoration surgery in primary cicatricial alopecia. Skin Appendage Disorders, 2 (1-2): 57-60.

8. Unger W, Unger R, Wesley $\mathbf{C}$ (2008): The surgical treatment of cicatricial alopecia. Dermatologic Therapy, 21 (4): 295-311.

9. Ors S, Ozkose M, Ors S (2015): Follicular unit extraction hair transplantation with micromotor: eight 
years experience. Aesthetic Plastic Surgery, 39 (4): 589 596.

10. Dua A, Dua K (2010): Follicular unit extraction hair transplant. Journal of Cutaneous and Aesthetic Surgery, 3 (2): 76-82.

11. Azar RP, Thomas AH, Maurer M et al. (2016): Alterations in Hair Follicle Morphology and Hair Shaft Production After Follicular Unit Transplantation. Am J Dermatopathol., 38 (10): 732-8.

12. Avram MR, Finney R, Rogers N (2017): Hair Transplantation Controversies. Dermatol Surg., 43 (2): 158-162.

13. Barr L, Barrera A (2011): Use of hair grafting in scar camouflage. Facial Plast Surg Clin North Am., 19: 55968.

14. Radwanski HN, Nuns D, Nazina F (2007): Follicular transplantation for the correction of various stigmas after rhytidoplasty. Aesthetic Plast Surg., 31: 62-8.

15. De Agustin JC, Morris SF, Zuker RM (1993): Tissue expansion in pediatric burn reconstruction. J Burn Care Rehabil., 14: 43-50.

16. Abo-Zeid MA, Elmaddawy AEA, El-Fahar MH et al. (2018): Selective Scalp Nerve Block: A Useful Technique With Tissue Expansion in Postburn Pediatric Alopecia. Ann Plast Surg., 80 (2): 113-120.

17. Unger WP, Shapiro R, Unger $M$ et al. (2010): Hair Transplantation. 5th ed. Informa Healthcare; London, Alopecia Reduction, Pp: 483-504.
18. Shao H, Hang H, Yunyun J et al. (2014): Follicular unit transplantation for the treatment of secondary cicatricial alopecia. Plastic Surgery, 22 (4): 249-253.

19. Tayyaba F, Amin MM, Attaur-Rasool S et al. (2015): Reconstruction of post burn scalp alopecia by using expanded hair-bearing scalp flaps. Pakistan Journal of Medical Sciences, 31 (6): 1405.

20. Handschel J, Schultz S, Depprich RA et al. (2013): Tissue expanders for soft tissue reconstruction in the head and neck area requirements and limitations. Clinical Oral Investigations, 17 (2): 573578.

21. Kim T, Chang WO, Bang JS et al. (2016): Moyamoya disease: treatment and outcomes. J Stroke, 18: 21-25.

22. Chen X, Lin CL, Su YC et al. (2018): Risk of subsequent stroke, with or without extracranialintracranial bypass surgery: a nationwide, retrospective, population-based study. J Neurosurg., 1: 1-8.

23. Qing Y, Cen Y, Liu Y (2006): Prevention and treatment of postoperative complication after skin soft tissue expansion for scar alopecia. Zhongguo Xiu Fu Chong Jian WaiKe Za Zhi., 20: 1193-95.

24. Saleh Y, Hafezi F, Naghibzadeh B et al. (2004): Scalp reconstruction using tissue expander. Egypt J Plast Reconstr Surg., 28: 71-5.

25. Rahimi H, Gharahdaghi M, Parsa A et al. (2013): Surgical management of acetabular fractures: a case series. Trauma Mon., 18 (1): 28-31. 